\title{
Análise da Cadeia Produtiva DA BATATA RENO DA REGIÃO DO VALE ZAMBEZE (MOÇAMBIQUE): GOVERNANÇA E COORDENAÇÃO
}

\section{RESUMO}

O presente estudo tem como objetivo analisar a cadeia produtiva e as determinantes das estruturas de governança e a coordenação sistêmica dos agentes da cadeia produtiva de batata reno no Vale do Zambeze em Moçambique do Vale do Zambeze, em Moçambique (África). Com base na Teoria dos Custos de Transação, são discutidas as estratégias contratuais de suprimento das unidades de produção de batata e comercialização atacadista. Na primeira fase desenvolveu-se o modelo de análise das relações contratuais na cadeia produtiva entre os seus segmentos em seguida fez-se a análise das transações do segmento produtor e comerciante atacadista ambulante. Essas análises buscam entender os arranjos contratuais e as estruturas de governança desse elo. Conclui-se que as atacadistas e os produtores apresentam três distintas formas de governança - uma de mercado, e duas híbridas: contratos implícitos e parceria na produção.

Palavras-Chaves: Cadeia Produtiva, Transação, Governança, Coordenação

\section{ABSTRACT}

In this study, we investigate the Irish potato production chain and the determinants of the transactions between the local farmers and intermediate (wholesale and retail) along the Zambeze Valley region in Mozambique. The theory of transaction costs was used to examine the current contractual strategies in use among the stakeholders of the Irish potato production chain. To understand the specificities of contractual mechanism, the role of the government and the legal issues, we firstly developed the model which encompasses the contractual relations in the production chain, which was followed by general description of stakeholders and the analysis of the transactions between the local farmers and wholesalers. A key result of our analysis is that both the local farmers and exporting intermediate are guided by three different marketing and contractual strategies, namely the implicit contracts, the partnership and integration in the production, and the free market strategy.

Key Words: Productive Chain, Transactions, Governance, Coordination
Júlio Ántónio

Mestre em Administração e Desenvolvimento Rural pela UFRPE

Docente na Universidade São Tomás de Moçambique

\section{Luiz Andrea Favero}

Romilson Marques Cabral Doutor em Administração pela UFBA

Mestre em Administração e Comunicação Rural pela UFRPE Especialista em Desenvolvimento Rural Integrado
Recebido em 24/dezembro/2009 Aprovado em 13/maio/2011 


\section{INTRODUÇÃO}

O sistema de abastecimento de alimentos moçambicano encontra-se em fase de transformação, decorrente dos seguintes fatores: internacionalização dos mercados com a entrada em vigor do Protocolo Comercial da Comunidade para o Desenvolvimento da África Austral em 2001, do desenvolvimento de novas tecnologias de informação; melhoria das infraestruturas de transporte; estabilização da inflação e das taxas de câmbio, liberalização dos preços e redução das tarifas de importação dos insumos. O processo é caracterizado por alterações significativas na base produtiva, as quais estão aumentando a interdependência dos segmentos produtivos e elevando a competitividade. Se, no curto prazo, a estrutura de governança é determinada pelos atributos da transação, no longo prazo, as estratégias individuais e coletivas podem definir o ambiente competitivo, institucional e tecnológico, modificando o formato da estrutura de governança.

Dentro desse contexto, a organização da cadeia produtiva de batata reno vem se alterando continuamente nos últimos 10 anos, em razão de modificações na composição da demanda final, da elevação do potencial de oferta e do crescimento da importância dos atacadistas
Contudo, sob a ótica da oferta, observou-se que a produção nacional de batata cresceu a uma taxa média de $28 \%$ nos últimos cinco anos. As mudanças da oferta são coordenadas pela introdução de novas variedades de sementes e pelas melhorias nas condições de transporte. A oferta de batata nacional com preços mais baixos que a importada está conquistando novos consumidores, principalmente das zonas suburbanas dos grandes centros urbanos.

De acordo com o Censo Nacional de 2007, a população de Moçambique é de 20,2 milhões de habitantes, sendo $29,8 \%$ população urbana e $70,2 \%$ rural (INE, 2009). O consumo da batata está concentrado nas zonas urbanas (grandes cidades). Segundo o MINAG (2008), as necessidades nacionais de batata são de 256 mil toneladas anuais. A participação da produção do Vale do Zambeze na oferta nacional é significativa, correspondendo aproximadamente a $54 \%$ do total da produção nacional. Dessa quantidade, são exportadas $56,1 \%$ para os mercados dos países vizinhos que fazem fronteira com a região do Vale do Zambeze. Assim, o deficit de batata em Moçambique é de cerca de 143,5 mil toneladas (56\%) considerado-se que uma pequena parte é importada dos países vizinhos (ver tabela 1).

na distribuição da batata em

Tabela 1 Produção, importação e exportação de batata reno Moçambique.

Sob a ótica da demanda, a conscientização a respeito dos benefícios de uma alimentação saudável tornou o consumidor mais exigente quanto ao nível de qualidade de hortaliças. A preocupação com os aspetos nutricionais dos alimentos aumentou a participação de hortaliças na cesta alimentar dos consumidores

\begin{tabular}{|c|c|c|c|c|}
\hline Ano & $\begin{array}{c}\text { Produção } \\
\text { nacional } \\
\text { (ton.) } \\
\text { (A) }\end{array}$ & $\begin{array}{c}\text { Importação } \\
\text { de batata para } \\
\text { consumo da } \\
\text { África do Sul } \\
\text { (ton.) } \\
\text { (B) }\end{array}$ & $\begin{array}{c}\text { Exportação } \\
\text { do Vale do } \\
\text { Zambeze (ton.) } \\
\text { (C) }\end{array}$ & $\begin{array}{c}\text { Consumo } \\
\text { aparente (ton.) } \\
\text { D = (A+B-C) }\end{array}$ \\
\hline 2003 & 55.375 & 256 & 7.195 & 48.436 \\
\hline 2004 & 63.285 & 236 & 14.317 & 49.204 \\
\hline 2005 & 141.640 & 2.568 & 60.000 & 84.208 \\
\hline 2006 & 169.756 & 11.090 & 67.902 & 112.944 \\
\hline 2007 & 142.841 & 8.430 & 58.403 & 92.868 \\
\hline
\end{tabular}
Fonte: elaboração do autor com base em dados das Alfândegas e do relatório dos Serviços Distritais de Atividade econômicas e governo distritais. urbanos, visto que nas zonas rurais a base da alimentação esta nas hortaliças, raízes e nos tubérculos. As principais alterações na composição da demanda final são provocadas pelo aumento do consumo de produtos que incorporam serviços, como conveniência, e produtos que reduzem o tempo de preparação da refeição, bem como pelas novas exigências alimentares da população, decorrentes do crescimento econômico e da melhoria na disseminação de informações e conhecimento.
O elevado deficit alimentar, a dependência das importações de batata reno e a abertura do mercado livre da SADC levaram o governo moçambicano a iniciar o processo de reestruturação da cadeia produtiva da batata para reduzir a dependência de batata importada e inserirse no novo ambiente econômico competitivo que se apresenta desde 2001 .

Abatata reno tem significativa importância econômica e social para o país. O seu cultivo é concentrado na região central, mais precisamente nas províncias de Manica, 
Sofala, Tete e Zambézia, que juntas produzem mais de $74 \%$ da produção nacional de batata reno. Segundo Demo, Domiguez e Walker (2006), a batata é uma das culturas alimentares e de rendimento que têm efeito no aumento da renda, e pertence a uma lista de 30 (trinta) com importância e potencial econômico para a redução da pobreza no Vale do Zambeze.

As oportunidades de comercialização agrícola têm crescido como o resultado do desenvolvimento e do estabelecimento de um ambiente aberto e operacional, que tem estado a permitir a recuperação da produção agrícola. Mas, os produtores de batata da região do Vale do Zambeze continuam a enfrentar problemas no acesso aos mercados de comercialização de produtos e insumos agrícolas. Os mercados rurais continuam em geral atrasados, com uma escala de operação muito pequena e fracas ligações com outras regiões do País, o que tem sido um dos principais entraves para o desenvolvimento do setor agrário. A pouca informação existente sobre a cadeia produtiva de batata reno e o potencial econômico, estimularam a realização da pesquisa. $\mathrm{O}$ seu objetivo é entender como se estabelecem as diferentes formas de governança nesses importantes elos da cadeia.

A base teórica em que se apoia o presente estudo é dada, principalmente, pelo modelo de análise do sistema agroindustrial, desenvolvido por Zylbersztajn (1995), que combina elementos da Teoria dos Custos de Transação (TCT). A pesquisa é exploratória e foram coletados dados secundários e primários com base em questionários aplicados aos agentes da cadeia.

$\mathrm{O}$ texto se divide em cinco partes. Primeiramente faz-se uma discussão da Teoria dos Custos de Transação e definem-se os conceitos de cadeia produtiva. $\mathrm{Na}$ segunda parte apresenta-se a metodologia. Na terceira parte delimita-se a cadeia produtiva. Em seguida, fazse a análise do modelo das estruturas de governança. $\mathrm{Na}$ quarta parte são analisadas as transações e estruturas de governança entre os produtores e comerciantes atacadistas e varejistas. Finalmente, na quinta e última parte, apresentam-se as considerações finais.

\section{REFERENCIAL TEÓRICO}

\subsection{Teoria dos Custos de Transação}

Segundo Willianson (1985), a unidade da análise central pela Teoria de Custos da Transação (TCT) é a transação. As características da transação determinam os custos transacionais envolvidos que, por sua vez, ditam a forma de governança vigente. Assim, a forma de governança é função das características da transação, cujas principais dimensões são frequência, incerteza e especificidade de ativo (WILLIAMSON, 1985).

A teoria aponta que uma maior frequência nas transações entre os mesmos agentes gera o que se chama de "reputação". O detalhe é que a reputação tende a reduzir os custos de transação tendo em vista não haver a necessidade de se buscar informações acerca do parceiro comercial e da qualidade do produto transacionado. Portanto, segundo a TCT, quanto maior a freqüência nas transações, maior o nível de reputação e consequentemente menores os custos de transação envolvidos.

A Incerteza relaciona-se ao desconhecimento dos agentes no que concerne aos elementos relacionados ao ambiente (econômico, institucional e comportamental), que exercem algum tipo de influência na gestão da cadeia de suprimentos. No campo organizacional, a fonte fundamental de incerteza decorre exatamente do suposto de racionalidade limitada e oportunismo dos agentes.

A especificidade de ativos refere-se a quanto o investimento no ativo é específico para a atividade e quão custosa é sua utilização alternativa em outra situação, a perda de valor do ativo, ainda, aos investimentos que são dedicados a um relacionamento de troca e não podem ser reempregados em usos alternativos. (WILLIANSON, 1985 e ARBAGE, 2004).

Segundo TCT há pelo menos seis tipos distintos de especificidade de ativos: a) especificidade locacional; b) especificidade física; c) especificidade ligada ao capital humano; d) especificidade de ativos dedicados à produção ou especificidade dedicada; e) especificidade de marca (mercadológica); e f) especificidade temporal. (ARBAGE, 2004).

Especificidade Locacional: essa situação ocorre quando uma determinada produção exige que outra, normalmente complementar (horizontal ou verticalmente) em termos de matéria-prima, se localize próximo. As especificidades locacionais envolvem a necessidade de proximidade a algum recurso natural, energético, de insumos, em relação a aspectos estratégicos vinculados a estoques, centros de distribuição e especificidades ligadas 
a pontos comerciais.

Especificidade Física: esse aspecto ocorre quando uma organização exige um dado padrão de matéria-prima dos seus fornecedores para ser utilizada em seu processo de produção. Relaciona-se, portanto, às características físicas do produto transacionado.

Especificidade ligada ao Capital Humano: essa especificidade está relacionada ao conjunto de conhecimentos idiossincráticos envolvidos direta e indiretamente nas transações.

Ativos dedicados à produção ou especificidade dedicada: esse aspecto seassocia aos ativos envolvidos na produção do produto transacionado e ocorre nos casos em que uma estrutura produtiva ou um determinado processo de produção são exigidos para a produção de um dado produto.

Especificidade de Marca (mercadológica): essa especificidade é ligada à construção de um nome, de uma marca, de uma reputação em um determinado mercado, do esforço de relações mais próximas com a comunidade, imprensa e os agentes do ambiente institucional, entre outras possibilidades. Também podem ser relacionados os esforços de

Figura 1 - Modelo de análise das estruturas de governança comunicação previstos noarranjodecoordenação estabelecido no posicionamento de um determinado produto, marketing, promoção de vendas, etc.

$$
\text { Especificidade }
$$

Temporal: $\quad$ essa especificidade está presente quando um determinado produto apresenta características de perecibilidade ou qualquer outra condição que implique a necessidade de consumo ou processamento (política de estoques da empresa focal) em um período de tempo predeterminado. (ARBAGE, 2004).

A TCT considera que as características comportamentais (racionalidade limitada e oportunismo) dos agentes envolvidos nas transações podem afetar os tipos de contratos existentes e a decisão por um ou outro tipo de estrutura de governança utilizada.

Williamson (1985), sustenta que o oportunismo

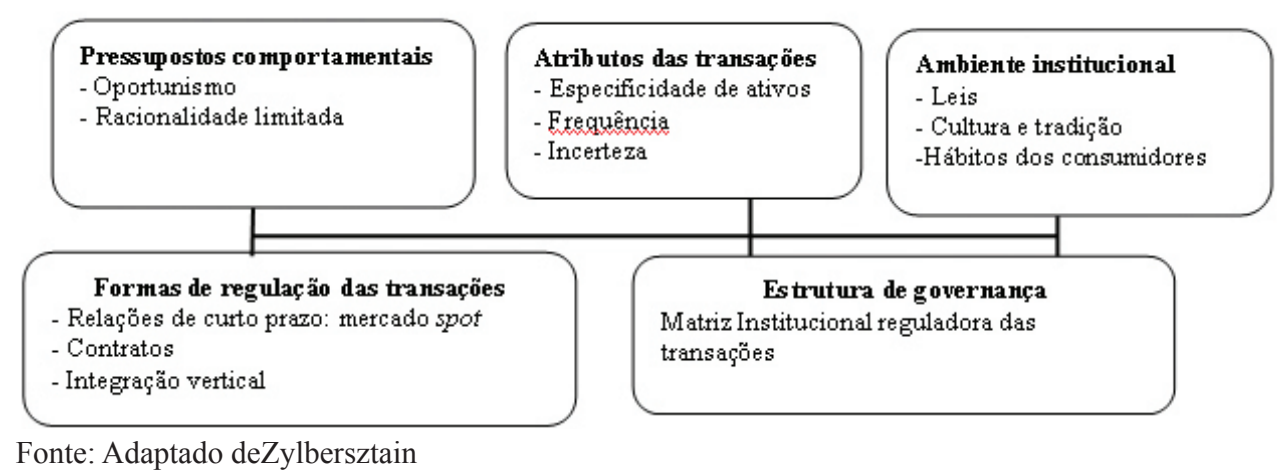
1973 apud GABRE-MADHIN, 2001). é a busca pelo interesse próprio com dolo, que inclui algumas formas mais flagrantes tais como a mentira, o roubo e o engano, mas não se limita a elas. O oportunismo compreende também algumas formas sutis de engano, que, nesse caso, incluem-se "as formas ativas e passivas e os tipos ex-ante e ex-post".

Segundo Williamson (1985) a racionalidade pode ser resumida em termos da condição de absoluta impossibilidade de os agentes dominarem e conseguirem processar a totalidade das informações necessárias para a tomada de decisão mais adequada na maioria das situações negociais.

Williamson (1985), considera estrutura de governança como matriz institucional em que a transação é definida. O autor caracteriza a matriz institucional como conjunto de regras, leis, contratos, normas formais e informais e regulamentos internos às organizações que governam institucionalmente uma transação. Na Figura 1 estão resumidos os elementos que condicionam a construção da estrutura de governança, nos arranjos interorganizacionais, à luz da TCT.

As instituições são definidas como "as regras do jogo", ambas as regras formais e informais como normas, convenções e códigos da conduta que fornecem a estrutura da interação humana (NORTH, 1990). As instituições surgiram para minimizar os custos de transação e facilitar as trocas no mercado. A evolução da troca pessoal pela troca impessoal ou anônima, apoiada por sistemas legais que forçam contratos, é o centro do processo de crescimento e desenvolvimento (NORH e THOMAS,

Considera-se, na realidade, que parcerias, joint ventures, franquias, arranjos cooperativos, coordenação 
vertical, entre outras participações societárias, são formas organizacionais alternativas ao mercado e à hierarquia, e que podem apresentar estruturas de governança particulares. Mesmo ao se analisar apenas as coordenações verticais, por exemplo, certamente haverá uma série de possibilidades alternativas de arranjos reguladores das transações (contratos mais ou menos hierarquizados, com ou sem cláusulas punitivas, contratos mais ou menos completos, com especificidades técnicas dos produtos transacionados ou não, e outros) e, consequentemente, diferentes mecanismos institucionais que regulem essas transações.

Os contratos são mecanismos de coordenação, considerando que apenas os preços não funcionam como coordenadores da produção. Muitos dos contratos consistem em promessas e entendimento não formalizados (ZYLBERSZTAJN, 1995). Assim, são de difícil imposição, e dependem de incentivos para que os indivíduos cumpram os termos de contrato.

MacNeil (1978) apud Arbage (2004) elaborou uma tipologia que classifica os contratos em clássicos, neoclássicos e relacionais. Williamson (1989), relacionou os atributos das transações com os tipos de contratos desenvolvidos por MacNeil (1978) e construiu uma tipologia de estruturas de governança vista no Quadro 1, abaixo.

Quadro 1. Formas eficientes de governança e atributos das transações

\begin{tabular}{|c|c|c|c|c|}
\hline Atributo da & & \multicolumn{3}{|c|}{ Características do investimento } \\
\hline \multirow{3}{*}{ Frequência } & & Não específico & Misto & Específico \\
\hline & Baixa & $\begin{array}{c}\text { Governança do } \\
\text { mercado (contrato } \\
\text { clássico) }\end{array}$ & $\begin{array}{c}\text { Governança } \\
\text { trilateral (contrato } \\
\text { neoclássico) }\end{array}$ & $\begin{array}{c}\text { Governança trilateral } \\
\text { ou Governança } \\
\text { unificada }\end{array}$ \\
\hline & Alta & $\begin{array}{l}\text { Governança do } \\
\text { mercado (contrato } \\
\text { clássico) }\end{array}$ & $\begin{array}{c}\text { Governança bilateral } \\
\text { (contratação } \\
\text { relacional) }\end{array}$ & $\begin{array}{l}\text { Governança unificada } \\
\text { (contrato relacional) }\end{array}$ \\
\hline
\end{tabular}

Williamson (1985), afirma que os contratos clássicos são aqueles nos quais todas as regras estão estabelecidas previamente de maneira formal, tendo, por conseguinte, consequências plenamente previsíveis. É um modelo estático que não apresenta margem para renegociações futuras.

Com o incremento da especificidade de ativos, mesmo em condições de baixa freqüência de transações, a governança do mercado vai deixando de ser eficiente, pois resulta em custos de transação crescentes. Nesses casos, contratos neoclássicos, baseados em estruturas de governança trilaterais, tendem a ser mais eficientes. A governança trilateral requer uma terceira parte para resolver as disputas quando as transações não são frequentes e existe a possibilidade de comportamento oportunístico entre os agentes. Diferentemente dos contratos clássicos, nos quais o ordenamento jurídico é suficiente, os contratos neoclássicos se fazem necessários quando há uma maior especificidade nos ativos transacionados e quando surge a necessidade da manutenção de uma relação de mais longo prazo entre os agentes. Portanto, a contratação neoclássica surge da necessidade de relações mais duradouras, sendo que se caracteriza pelo desejo mútuo de manutenção do acordo. Admite uma maior flexibilidade de ajustes posteriores, utiliza-se normalmente do contrato anterior como base de negociação e também, por vezes, exige uma arbitragem de terceiros quanto a eventuais disputas (ARBAGE, 2004).

Quando ocorre uma maior frequência nas transações e há necessidade de ativos mais específicos ainda, a governança bilateral, baseada em contratos relacionais, passa a ser indicada como o modo de organização mais eficiente. O pressuposto básico dos contratos relacionais é que os agentes tendem a privilegiar a continuidade nas relações. Além disso, os contratos relacionais preveem a possibilidade de revisão permanentedascláusulas em decorrência de alterações ambientais, configurando, então, um sistema em constante negociação. Finalmente, quando a especificidade dos ativos é muito significativa, a estrutura de governança que minimiza os custos de transação tende a ser a hierarquia - integração das atividades em uma organização (ARBAGE, 2004).

É largamente reconhecido que as transações de mercado, em particular em países em desenvolvimento, muitas vezes são embutidas em relações personalizadas de longo prazo. A troca personalizada surgiu em resposta ao fracasso de compromisso, no qual o risco da violação de contrato ou oportunismo é alto, resultando da falta 
da regulação de informações no mercado inadequada e à ausência de mecanismos de execução legais. As instituições constroem a confiança e promovem a reputação e capital-social - tal como as associações comerciais, as redes de solidariedade, e os grupos de laços étnicos ou religiosos, emergem para lograr o fracasso de compromisso (GABRE-MADHIN, 2001).

\section{COORDENAÇÃO SISTÊMICA}

Farina e Zylbersztajn (1994) resumem o conceito de coordenação de uma forma mais operacional. Segundo esses autores, a coordenação pode ser entendida como “... a habilidade de transmitir informação, estímulos e controle ao longo das etapas sequenciais que integram o conjunto de atividades necessárias para atender o mercado."

"Há pelo menos duas dimensões para lidar com a coordenação de sistemas agroindustriais. A primeira se refere aos modos de governança resultantes das características das transações e a segunda, às características da coordenação resultantes do ambiente organizacional e institucional. Ambas interagem dando a forma final do modo de governança do sistema" (ZYLBERSZTAJN, 1995).

Segundo FURLANETTO, (2000),

“[...] a estrutura de coordenação sistêmica assume diferentes formas, que dependem, dentre outros fatores, do ambiente institucional, das características econômicas das transações (ativos específicos, frequência, risco, incerteza e contratos), das características sociais das relações verticais (confiança, status e interesses comuns) e das características básicas das relações verticais (interdependência, cooperação e competitividade)".

Este trabalho considera a coordenação como a habilidade de transmitir informação, estabelecer medidas de orientação e assistência, conduzir estímulos e implementar medidas de controle ao longo das etapas sequenciais de produção, visando adequar os objetivos de eficiência da cadeia produtiva aos interesses do consumidor. As estruturas de coordenação sistêmica são as medidas operacionais com base nas quais as redes de cooperação, as organizações procuram efetivamente organizar e coordenar as transações. Assim, do lado dos mecanismos de coordenação, o esquema de análise fica composto por quatro subsistemas subsistema de informação, subsistema de incentivo, subsistema de controle e subsistema de orientação e assistência.

\subsection{Cadeia Produtiva}

A evolução recente do estudo dos sistemas agroindustriais está centrada na questão relativa à coordenação eficiente das cadeias produtivas. O elevado grau de interdependência dos setores produtivos industrial, agrícola e de serviços faz com que a dinâmica individual de cada agente passe a influenciar diretamente todos os outros agentes da cadeia produtiva.

Segundo Silva (2002) "[...] uma cadeia produtiva engloba fornecimento de insumos e equipamentos, produtores, indústrias, distribuidores, atacado e varejo". "Além disso, é envolvida por um ambiente institucional e organizacional". O ambiente institucional refere-se ao conjunto de leis, ao padrão cultural e às tradições da sociedade e do hábito dos consumidores que se relacionam diretamente com a cadeia produtiva. O ambiente organizacional refere-se às organizações que exercem influência sobre os componentes da cadeia, como, por exemplo, as instituições de crédito e assistência técnica, órgãos governamentais, organismos não governamentais, associações de classe, etc. Há uma forte interdependência desses processos, cujo sucesso depende da interação eficiente de todos os elos da cadeia.

O elevado grau de interdependência dos setores produtivos industrial, agrícola e de serviços faz com que a dinâmica individual de cada agente passe a influenciar diretamente todos os outros agentes da cadeia produtiva. $\mathrm{O}$ entendimento das cadeias produtivas como uma sequência de ações permite avaliar cada ação ao longo da cadeia como um contrato entre os agentes. A ECT disponibiliza um quadro analítico que permite compreender uma grande diversidade de arranjos contratuais. Especificamente, "[...] a ECT permite explicar a organização dos sistemas produtivos como um conjunto de relações contratuais verticais, formais ou informais, que representam estruturas de governança intersegmentos que variam da governança de mercado à integração vertical" (FARINA et al. , 1997).

Segundo Machado (2002), "[...] a cadeia produtiva pode ser vista como um anexo de contratos informais e 
formais, cujo objetivo é fornecer estímulos, controles e agilizar o fluxo de informações ao longo de todos os segmentos do sistema". Dentro do contexto proposto pelo NEI, o aparato metodológico da teoria dos contratos amplia o escopo analítico para o âmbito da cadeia produtiva em detrimento da visão centrada na agricultura, o que permite o tratamento das mudanças das relações entre os segmentos. Assim, a análise das relações contratuais propicia a visualização do modo como os agentes na cadeia produtiva dividem o risco associado à produção e à variabilidade de preço, bem como à influência de ambos, tanto na distribuição quanto no nível de qualidade do produto disponível no mercado. O foco central das análises são as transações que interligam os agentes.

\section{METODOLOGIA}

\subsection{Caracterização da Região de Estudo}

O Vale do Zambeze localiza-se entre os paralelos $14^{\circ}$ e $19^{\circ}$ latitude sul, prolonga-se até o ponto ocidental de Moçambique, cerca do meridiano $30^{\circ}$ a leste de Greenwich. É composto por quatro províncias, abrangendo a totalidade da província de Tete, com área de 100.000 km2; metade da província da Zambézia 50.000 km2; cerca de $40.000 \mathrm{~km} 2$ da província de Sofala e de 30.000 $\mathrm{km} 2$ da província de Manica. No total, a região ocupa uma área de $225.000 \mathrm{~km} 2$ (cerca de 27,7\% da superfície do país). A região possui um clima tropical de altitude nas terras altas de interior. A umidade relativa varia na época chuvosa entre $90-100 \%$. As temperaturas médias anuais variam entre 18 e $24^{\circ} \mathrm{C}$. Durante o inverno, em áreas montanhosas, podem registrar-se temperaturas mínimas absolutas de $3^{\circ} \mathrm{C}$. O valor médio anual de precipitação é superior a $1.200 \mathrm{~mm}$, podendo exceder a $2.400 \mathrm{~mm}$. As deficiências hídricas são, em regra, baixas: entre um três meses, mais excepcionalmente quatro. Existe na região uma área de cerca de 6,5 milhões hectares de potencial para a exploração agropecuária e predominam solos vermelhos ferralíticos, com textura pesada.

\subsection{Coleta de Dados}

O estudo pode ser caracterizado como pesquisa exploratória que, segundo Mattar (1994), ajuda o pesquisador a estabelecer as prioridades a estudar. Ainda segundo o autor, os métodos utilizados pela pesquisa exploratória são bastante amplos e versáteis e compreendem: levantamento em fontes secundárias, levantamento de experiências, observação informal e amostragem por acessibilidade. Foram aplicados questionários qualiquantitativos aos produtores, aos intermediários (atacadistas e varejistas) e a outros agentes da cadeia. Ao todo foram realizadas entrevistas com 49 produtores de batata reno; 20 comerciantes atacadistas ambulantes; 10 comerciantes varejistas dos mercados e feiras livre, 3 barracas de venda de insumos agrícolas especializada; 7 representantes do ambiente institucional - Associação de Produtores de Batata; Associação dos Vendedores de Batata do Mercado Kwachena e Biri-Biri; técnicos dos serviços de agricultura; serviços de comércio e indústria; instituições financeiras; Apoio às Iniciativas Privadas no Setor Agrário (ADIPSA).

A pesquisa de campo foi realizada na região do Vale do Zambeze, a mais representativa de Moçambique na produção e na comercialização de batata. De acordo com Demo, Domiguez e Walker (2006), os distritos citados produzem $90 \%$ da produção de Moçambique. Para levantamento de dados de produção, os produtores foram selecionados com base na acessibilidade e nas informações de produção obtidas nos relatórios dos serviços provinciais de agricultura. Para os intermediários, também foi usado o critério da acessibilidade. Os dados de comercialização foram obtidos nos Mercados de BiriBiri e Tete Bene, na Região do planalto de Angónia, no Mercado Kwachena e no Mercado $1^{\circ}$ de Maio, na cidade de Tete, no Mercado Maquinino, na cidade da Beira, no Mercado 25 de Junho, na cidade de Chimoio e no Mercado Central de Quelimane. A pesquisa foi realizada no período de Janeiro a Agosto de 2009, em

Moçambique.

\subsection{Análise dos Dados}

No primeiro momento a análise foi direcionada para o entendimento da cadeia como um todo, avaliando-se todos os elementos constituintes da sua estrutura assim como os elementos externos que a influenciam.

Em seguida, os agentes da cadeia foram identificados e caracterizados: quem eram os fornecedores de insumos agrícolas, os produtores, os comerciantes atacadistas e varejistas e os consumidores finais, o 
que faziam e como faziam são algumas das questões respondidas. No momento seguinte, foram estabelecidos os relacionamentos existentes entre produtores e intermediários, ou seja, foram identificados quais deles transacionam entre si, determinando-se os fluxos físicos e de informações existentes.

A seguir, a estrutura da cadeia produtiva foi investigada com o enfoque nos aspectos institucionais e ambientais, de modo a se verificar o papel das associações e organizações ligadas à cadeia, nos seus aspetos culturais - tais como costumes, tradições e preferências dos consumidores e aos aspetos de interação com agentes internacionais (públicos e privados) também foram considerados.

\subsection{O Modelo de Analise das Transações}

O esquema de análise é composto pela estruturação da cadeia produtiva e pelas categorias analíticas com base na TCT (fig. 1 p. 4). As categorias analíticas são exatamente os pressupostos de natureza cognitiva e comportamental dos agentes e os principais atributos das transações, e compõem parte do esquema preliminar de pesquisa. São elas: Oportunismo e Racionalidade Limitada, os determinantes da estrutura de governança: Incerteza, Especificidade de Ativos, Frequência e Ambiente Institucional.

\subsubsection{Análise das}

\section{Transações}

A cadeia produtiva compreende um grande número de agentes e de transações relacionados por meio de complexas interações. Sendo assim, fez-se necessário delimitar o conjunto de agentes e transações a serem analisados mais profundamente, ou seja, a $\mathrm{T} 2$.

Uma vez identificadas essastransações, prossegue- se para a avaliação dos pressupostos comportamentais oportunismo e racionalidade limitada - e para a análise dos atributos das transações: especificidade de ativos, incertezas e frequência. $\mathrm{O}$ estudo desses atributos foi feito levando-se em conta os agentes de ambos os lados da transação. Após o estudo, buscou-se entender as formas de regulação das transações e, por último, interpretar a identificação das formas de governança sugeridas pela TCT.

\subsubsection{Análise dos Contratos}

Analisou-se os contratos atrelados às transações enfocadas, os mecanismos de incentivos (bonificações, descontos, entre outros), os controles (a exemplo de penalidades e multas) previstos antecipadamente (ex ante) e os dispositivos de adaptação às questões não previstas (ex post). Viu-se também os aspetos de arbitragens e das salvaguardas contratuais, inclusos aqui a apreciação dos mecanismos de monitoramento e controle, e o acesso às informações demandadas pelos agentes. A análise contratual, adicionalmente, precisa abarcar a questão da duração (ex ante) e da continuidade (ex post) dos contratos (ZYLBERSTAJN e LAZZARINI, 1997).

\section{A CADEIA PRODUTIVA DA BATATA}

\subsection{Delimitação da Cadeia}

Figura 3 - Delimitação simplificada da cadeia produtiva de "Batata Reno" da Região do Vale do Zambeze (Moçambique)

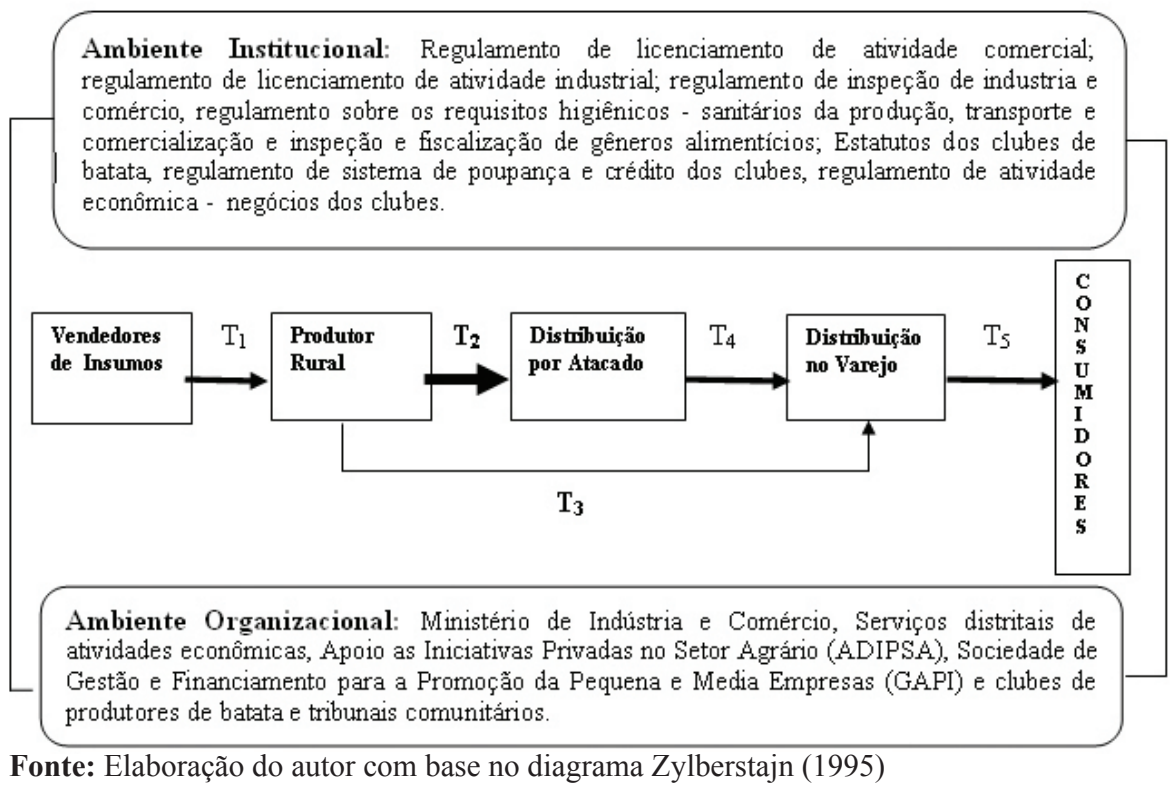

Fonte: Elaboração do autor com base no diagrama Zylberstajn (1995) 
A cadeia produtiva da batata reno da região do planalto de Angónia esta delimitada de acordo com a Figura 2 . Os segmentos que definem a sua configuração são apresentados acima e envolvem: fornecedores de insumos agrícolas; a produção primária, distribuição, consumidores e os ambientes, institucional e organizacional.

\subsubsection{Fornecedores de Insumos}

A oferta de insumos agrícolas em Moçambique ainda é bastante incipiente. Atualmente a batata-semente certificada é distribuída via crédito, pelos Serviços Distritais de Atividades Econômicas. A batata-semente local é comercializada em feiras locais, e o restante dos insumos - fertilizantes e agrotóxicos - é comercializado por vendedores informais e formais nos mercados, nas barracas e nas lojas da região do Vale do Zambeze.

\subsubsection{Segmento da Produção: Caracterização dos Produtores e Sistema de Produção}

O segmento de produção, na cadeia produtiva da batata da Região do Planalto de Angónia, é composto por 39.808 produtores (Demo et al., 2006). De acordo com o Ministério da Agricultura (2006), a estrutura do Sector Agrícola Moçambicano é dominada por pequenas explorações agrícolas, representando 99,0\%, e o restante, $1,0 \%$, composto por médias e grandes explorações. A maior parte da batata comercializada provém de explorações com área menor que 3,0 ha, tipicamente entre 0,5 e 2,0 ha. A mão de obra é constituída basicamente por agregado familiar; todavia, em tarefas que exigem produtores, no geral, utilizam poucos insumos modernos (agroquímicos), maquinaria e crédito. Cerca de 95,0\% dos pequenos na região do planalto de Angónia cultivam a variedade Rosita (variedade local). Pouco mais de 5,0\% dos pequenos produtores cultivam o BP1, o Mondial e a Lizeta, que são variedades certificadas. O BP1 é importado da África do Sul, e o Mondial e a Lizeta importadas da Holanda. O rendimento médio da batata reno na região de Angónia é de 9,3 t/ha cultivando-se cerca de 7.901 ha. O custo de produção médio é de US\$2,037/há, o que corresponde a um retorno médio de US\$2,130/ha/safra.

Os produtores de batata reno são, em geral, vendedores líquidos e podem escolher vender o seu produto na fazenda, no mercado local ou no regional. Segundo a pesquisa, 95\% dos produtores inquiridos vendem batata. Nas transações com atacadistas, $16 \%$ dos produtores fornecem a crédito. Os atacadistas ambulantes representam $74 \%$ dos clientes, seguidos pelos atravessadores dos mercados rurais, com $24 \%$, e finalmente o produtor vizinho, com $2 \%$.

$\mathrm{O}$ maior grupo de produtores vende na fazenda, $50,3 \%$. O mercado terminal é Biri-wiri, com 38\% das transações realizadas pelos produtores. Esse mercado não tem infraestruturas, como água canalizada, sanitários e espaço coberto para albergar os agentes do mercado. A análise mostra que a Rosita é mais comercializada pelos produtores, tanto na fazenda como no mercado de Biri-wiri. Os produtores vendem mais a variedade BP1 nos mercados das zonas urbanas (Kwachena, Nampula e Maquinino). As variedades comercializadas estão distribuídas na tabela 2. maior quantidade de trabalho, são utilizados esquemas tradicionais de interajuda. Os meios de produção são rudimentares, com predominância da enxada e tração animal. A produção é realizada em duas safras - a safra seca e a chuvosa. O sistema de cultivo dominante é a monocultura e os
Tabela 2. Distância, quantidade e preços de venda da batata reno pelo produtor

\begin{tabular}{|c|c|c|c|c|c|c|}
\hline \multirow[t]{2}{*}{$\begin{array}{c}\text { Distribuição } \\
\text { da batata pelo } \\
\text { produtor }\end{array}$} & \multirow[t]{2}{*}{$\begin{array}{c}\text { Localização } \\
\text { em relação } \\
\text { a Tsangano } \\
(\mathbf{K m})\end{array}$} & \multicolumn{2}{|c|}{$\begin{array}{c}\text { Quantidades } \\
\text { variedades } \\
\text { transacionadas } \\
\text { pelos produtores na } \\
\text { safra 2007/08 (Ton.) }\end{array}$} & \multicolumn{2}{|c|}{$\begin{array}{c}\text { Preço por } \\
\text { variedade (US\$/ } \\
\mathrm{kg})\end{array}$} & \multirow[t]{2}{*}{$\begin{array}{c}\text { Percentual } \\
\text { de venda } \\
\text { realizada pelo } \\
\text { produtor por } \\
\text { mercado }(\%)\end{array}$} \\
\hline & & $\mathrm{BP} 1$ & Rosita & $\mathrm{BP} 1$ & Rosita & \\
\hline Fazenda & ------ & 405 & 696 & 0,41 & 0,18 & 50,31 \\
\hline Mercado Biri-wiri & 68 & 230 & 613 & 0,5 & 0,20 & 38,50 \\
\hline $\begin{array}{l}\text { Mercado Kwachena } \\
\text { (Tete) }\end{array}$ & 250 & 160 & 34 & 0,38 & 0,30 & 8,87 \\
\hline $\begin{array}{l}\text { Mercado da faina } \\
\text { (Nampula) }\end{array}$ & 800 & 10 & 4 & 1,25 & 1,04 & 0,17 \\
\hline $\begin{array}{l}\text { Mercado Maquinino } \\
\text { (Beira) }\end{array}$ & 820 & 37 & 11 & 1,04 & 0,83 & 2,15 \\
\hline Total & 1912 & 852 & 1.358 & & & 100 \\
\hline
\end{tabular}

Fonte: Elaboração pelo autor com base em dados da pesquisa 
As variedades BP1 e Rosita comercializadas no mercado de Biri-wiri, alimentam os mercados nacionais de Cuamba, Quelimane, Nacala e Nampula. O mercado Maquinino é um dos mais exigentes da região central do país. Os produtores levam as variedades brancas BP1, Liseta e Mondial. Segundo um dos grandes produtores que vende batata na Beira, BP1, é uma variedade muito procurada, e o principal entrave é a distância entre a zona de produção e a área de consumo.

\subsubsection{Distribuição: Atacado e Varejo}

A comercialização da batata por atacado é organizada fundamentalmente por comerciantes atacadistas ambulantes, os quais se deslocam às explorações agrícolas e aos mercados do produtor para aquisição de produtos. Uma parte de produtores transportam a batata reno para os mercados atacadistas e varejistas dos grandes centros urbanos (transações T2 e T3). Os fluxos da batata reno na região do Vale do Zambeze são dispersos. Das regiões produtoras partem os fluxos para os mercados terminais rurais e dos centros urbanos. A análise da distribuição realizada por atacadistas, varejistas ambulantes e por produtores verticalizados mostra que o mercado de Biri-wiri é o principal local da venda da batata. Nesse mercado, foram realizadas $64 \%$ das transações, seguido do mercado de Kwachena e arredores da cidade de Tete com $15 \%$, e na terceira posição vem o mercado de central de Quelimane, com 9\% dos entrevistados. Os outros mercados foram Maquinino e a cidade de Nampula.

A distribuição distrital da batata reno é assegurada por meio de bicicletas, tratores e pequenos caminhonetas de até 7 toneladas. $\mathrm{O}$ setor de transporte que predomina nesse nível é informal. O transporte do mercado terminal até os mercados das principais cidades é efetuado pelo setor "formal", mais veículos estrangeiros (a operarem ilegalmente).

O Mercado da cidade de Nampula, que fica a cerca de $800 \mathrm{~km}$, é o que tem o preço mais alto por $\mathrm{kg}$ de batata transacionada (U\$S 0,78/kg). No preço foi subtraído o custo do transporte. Em segundo lugar, vem o mercado de Quelimane, com U\$S 0,72/kg e o de Kwachena, com U\$S $0,25 / \mathrm{kg}$. Esses mercados são todos nacionais. O mercado de Biri-wiri para onde converge toda a produção, apresenta o preço mais baixo, U\$S 0,21/kg. O valor médio por transação em um dado mercado é calculado como o produto dos quilos médios vendidos por transação pelo preço de venda, menos o custo de transporte. O total as transações rederam cerca de 31 milhões de dólares americanos. O mercado de Biri-wiri é o líder, tendo movimentado cerca de U\$S14,4 milhões, seguido de Kwachena, com cerca de 9,4 milhões, e o mercado de Quelimane, com cerca de 5,7 milhões. A tabela 3 mostra os principais mercados, a quantidade e o valor arrecadado por cada mercado nas transações.

Os varejistas das feiras e dos mercados urbanos são os principais vendedores aos consumidores. Eles adquirem a batata nos mercados distribuidores das cidades de Tete, Chimoio, Beira, Quelimane e Nampula. Os intermediários atacadistas dos mercados da Beira e Quelimane vendem a batata a crédito e os outros mercados à vista. De acordo com a pesquisa, $88 \%$ dos entrevistados são pequenos comerciantes que fazem negócio por conta própria e somente $12 \%$ são firmas privadas de médio porte. Os gestores do negócio são indivíduos com e sem formação básica. Aqueles que não têm nenhuma formação representam $20 \%$ dos entrevistados, com nível primário $73 \%$, e nível secundário representa $1 \%$. O nível de experiência no negócio com a batata reno é alto. Dos

Tabela 3 Participação no mercado e valor da transação na safra 2007/08

\begin{tabular}{|c|c|c|c|c|c|c|c|}
\hline \multirow[b]{2}{*}{$\begin{array}{l}\text { Mercado de venda } \\
\text { pelo produtor }\end{array}$} & \multicolumn{4}{|c|}{$\begin{array}{c}\text { Distância entre zona de produção e o } \\
\text { mercado }\end{array}$} & \multicolumn{3}{|c|}{$\begin{array}{c}\text { Participação no mercado e valor da } \\
\text { transação safra 2007/08 }\end{array}$} \\
\hline & $\begin{array}{c}\text { Estrada } \\
\text { degradada } \\
(\mathrm{km})\end{array}$ & $\begin{array}{l}\text { Boa } \\
\text { estrada } \\
(\mathrm{Km})\end{array}$ & $\begin{array}{l}\text { Total } \\
(\mathrm{Km})\end{array}$ & $\begin{array}{c}\text { Participação } \\
\text { no mercado } \\
(\%)\end{array}$ & $\begin{array}{l}\text { Quantidade } \\
\text { média } \\
\text { vendida por } \\
\text { transação } \\
\text { (ton.) }\end{array}$ & $\begin{array}{l}\text { Preço de } \\
\text { venda } \\
\text { menos custo } \\
\text { transporte } \\
\text { (USS/kg) }\end{array}$ & $\begin{array}{l}\text { Valor } \\
\text { médio da } \\
\text { transação } \\
(\mathrm{US} \$) * 10^{3}\end{array}$ \\
\hline Biri-wiri (Tsangano) & 68 & & 68 & 61,54 & 68.734 & 0,21 & 14.434 \\
\hline Khachena e outros & 20 & 224 & 244 & 21,62 & 24.152 & 0,39 & 9.419 \\
\hline $\begin{array}{l}\text { Faina Nampula } \\
\text { Central -Quelimane }\end{array}$ & 277 & 503 & $\begin{array}{l}800 \\
850\end{array}$ & $\begin{array}{l}5,13 \\
7,12\end{array}$ & $\begin{array}{l}5.725 \\
7.956\end{array}$ & $\begin{array}{l}0,78 \\
0,72\end{array}$ & $\begin{array}{l}4.466 \\
5.728\end{array}$ \\
\hline Maquinino - Beira & 50 & 800 & 850 & 4,01 & 4.480 & 0,56 & 2.509 \\
\hline 25 de Junho - Chimoio & 50 & 600 & 650 & 0,58 & 650 & 0,66 & 429 \\
\hline Total & 388 & 1.584 & 1.992 & 100 & 111.697 & & 36.985 \\
\hline
\end{tabular}

Fonte: Elaboração pelo autor, com base em dados da pesquisa 
varejistas entrevistados, $94 \%$ vendem batata reno há mais de cinco anos.

A venda de batata nos mercados urbanos é feita em unidades padronizadas (o peso). Nos mercados das zonas rurais, a batata é vendida em unidades não padronizadas, latas e baldes de 7, 15 e 20 litros (ver Figura 20). Não existe norma de padronização para a batata. Por isso, antes da venda, alguns varejistas, $18 \%$, fazem a seleção de acordo com o tamanho e a aparência visual, e embalam em sacos de 10,0 kg para agregar valor no produto. O que resta é comercializado ao peso, e o consumidor é livre para escolher. O fluxo da batata é regular, existindo disponibilidade de batata ao longo do todo o ano. Segundo os varejistas, a qualidade do produto é boa, pois $45 \%$ dos varejistas citaram ser boa e $20 \%$ afirmaram ser muito boa. O principal fornecedor do varejista é o atacadista ambulante, 94\% do total das firmas varejistas entrevistadas. Um pequeno grupo de varejistas vai até as zonas de produção para comprar a batata (6\%). Na Tabela 24 são descritas a estrutura e as relações no mercado da batata.

\subsection{Comportamento de Consumidores}

Os consumidores compram a batata diretamente do produtor; os distribuidores urbanos, do comerciante atacadista nos mercados; os varejistas, nas feiras e nos mercados rurais e urbanos. As preferências de consumo variam entre o norte, o centro e o sul de Moçambique. Na região sul, os consumidores preferem variedades de batata de polpa branca, como o BP1, a Liseta, o Mondial e outras. Nas regiões centro e norte, o consumo divide-se entre as variedades brancas e as vermelhas. Nas grandes capitais como Beira, Chimoio e Quelimane, o consumo tende para as variedades brancas, enquanto nas cidades de Nampula, Nacala e Tete os consumidores optam pela variedade vermelha (Rosita). De acordo com os varejistas, alguns consumidores, ao adquirirem a batata, têm propensão a preocupar-se com a sua origem. Assim, $50 \%$ consumidores preferem a batata nacional, 25\% adquirem a batata importada e os outros $25 \%$ adquirem tanto a batata nacional como a importada, desde que apresente a qualidade desejada. Contudo, o preço constitui o elemento determinante na compra do produto. Os varejistas afirmaram que $75 \%$ dos consumidores decidem comprar na base do preço e $25 \%$ olham primeiro a qualidade e depois os preços, que pode indicar uma tendência de consumo exclusivo de produtos saudáveis.

\subsection{Ambiente Institucional e Organizacional}

O ambiente organizacional compreende organizações corporativas, clubes de produção de batata, órgãos públicos e privados, e institutos de pesquisa vinculados ao governo do Estado.

Os clubes de produção de batata e as associações de produtores têm a função de defender os interesses comuns dos associados nos diversos segmentos, e, especialmente, no que se refere às questões crédito em instituições financeiras e em órgãos públicos. Apesar disso, ainda existem muitas atividades e desafios para esses grupos trabalharem em sintonia com o mercado e outros serviços.

Os Serviços Distritais de Atividades Econômicas têm a função de acompanhar o desenrolar da produção agropecuária da região, distribuição de sementes, assistência técnica, identificação de problemas e de propor soluções.

O Instituto de Investigação Agrária de Moçambique (IIAM) tem por missão gerar e difundir inovações e tecnológias para o desenvolvimento sustentado da agropecuária. Na batata reno estão sendo testados 8 clones provenientes de CIP-Quénia. O Centro Internacional de Batata (CIP) participa no programa de melhoramento genético nacional de novas variedades de batata.

Os produtores e comerciantes rurais recebem informações via intermediários ambulantes (atravessadores) que saem das grandes cidades para comprar a batata e transportá-la para esses centros. Semanalmente o Ministério de Agricultura e o Ministério da Indústria e Comércio divulgam boletins sobre mercados de diversos produtos nos diferentes canais de informação (rádios comunitárias, jornais eletrônico, jornal notícia) e periodicamente são publicados os boletins, por via eletrônica.

Apesar de existir regulamento sobre: licenciamento da atividade comercial e industrial; inspeção da indústria e comércio; requisitos sanitários da produção, transporte, comercialização e inspeção e fiscalização de gêneros alimentícios; importação e exportação de produtos agrícolas, e estratégias à comercialização agrícola, durante a pesquisa observou-se nos principais mercados rurais 
que o comércio é informal, sem fiscalização das normas, até com exportação ilegal da batata reno para Malawi e Zambia. A exportação de batata reno para mercados dos países vizinhos é ilegal porque ela não obedece às regras impostas pelos regulamentos antes citados e não existe nenhum agente do Estado ou sociedade civil que registre a quantidade de batata destinada ao mercado externo. Apesar de as exportações serem ilegais, ela constitui um canal disponível para a comercialização da batata reno dessa região em razão da existência de poucos intermediários nacionais disponíveis para transportar batata e distribuí-la no mercado nacional. Os produtores defendem a criação de normas de padronização e fiscalização da comercialização de produtos agrícolas, pois se sentem prejudicados por estarem, de certa forma, sendo excluídos do mercado nacional e receberem preços baixos nas vendas aos intermediários dos países vizinhos (Malawi, Tamzania e Zambia).

No crédito para comercialização agrícola existem programas orientados para a comercialização fornecidos por ONGs, bancos de micro crédito e fundos de apoio ao mais adequada na maioria das situações comerciais.

$\mathrm{Na}$ pesquisa, observou-se que $43 \%$ e $21 \%$ dos produtores e atacadistas, respectivamente, não sabem ler nem escrever. Mas, os atacadistas têm a vantagem de trocar informações diariamente com varejistas e atacadistas amigos, bem como colher informações da rádio. As trocas de informações com outros atacadistas representam $88 \%$ das fontes de informação, seguidas das informações de estivadores, com $11 \%$, e finalmente vêm órgãos de informação - como rádio, jornal -, com 1 $\%$ das fontes usadas pelos atacadistas. Tais informações conferem maior racionalidade aos atacadistas que aos produtores no mesmo nível. Essa dificuldade é aproveitada pelos compradores para definirem os preços de compra da batata. Contudo, a racionalidade é reduzida pelo compartilhamento de informações entre os produtores vizinhos, visto que todos os produtores trocam informações sobre os preços e sobre o comportamento dos intermediários duma determinada região. Pela Tabela 3 mostra-se os resultados da busca de informações e da negociação de preços pelos produtores.

desenvolvimento

Tabela 3. Busca de informação sobre os mercados e preços de batata reno

\begin{tabular}{|c|c|c|c|}
\hline & \\
\hline local dos & Descrição da variável & Descrição & $\begin{array}{l}\text { Perceta- } \\
\text { gem }(\%)\end{array}$ \\
\hline \multirow{4}{*}{$\begin{array}{l}\mathrm{g} \text { o } \mathrm{v} \text { e } \mathrm{r} \text { n o } \mathrm{s} \\
\text { distritais. Mas o } \\
\text { acesso é limitado }\end{array}$} & \multirow{3}{*}{$\begin{array}{l}\text { Tempo de informação do } \\
\text { preço }\end{array}$} & \multicolumn{2}{|l|}{ Quando soube do preço da batata? } \\
\hline & & Na hora de venda & 18,4 \\
\hline & & $\begin{array}{l}\text { Dias antes } \\
\text { Houve diferenca entre } 0 \text { preco recebido e }\end{array}$ & 81,6 \\
\hline & \multirow{2}{*}{ Conhecimento do preço } & $\begin{array}{l}\text { Houve diferenca entre o preco recebido e prec } \\
\text { Preco pago mais baixo que o conhecido }\end{array}$ & 46,9 \\
\hline \multirow{2}{*}{ a comerciantes } & & Preço pago semelhante/mais alto que o conhecido & 53,1 \\
\hline & \multirow{2}{*}{ Tempo de acordo do preço } & \multicolumn{2}{|l|}{ Quando teve o acordo do preço? } \\
\hline formais dos & & $\begin{array}{l}\text { No momento da venda } \\
\text { Por acordo prévio }\end{array}$ & $\begin{array}{l}98,0 \\
2,0\end{array}$ \\
\hline centros urbanos & \multirow{2}{*}{$\begin{array}{l}\text { Negociação do preço com } \\
\text { o intermediário }\end{array}$} & \multicolumn{2}{|l|}{ Quanto tempo leva para negociar o preco? } \\
\hline e não atinge os & & $\begin{array}{l}\text { Menos de } 30 \text { minutos } \\
\text { Mais de } 30 \text { minutos }\end{array}$ & $\begin{array}{l}62.5 \\
37,5\end{array}$ \\
\hline
\end{tabular}

vendedores informais dos mercados rurais.

\section{CARACTERÍSTICAS DAS TRANSAÇÕES}

\subsection{Transação 2 - Produtores Rurais e Comerciantes Atacadistas Ambulantes}

A transação T2 refere-se a compras efetuadas pelo atacadista ao produtor agrícola. Trata-se da forma predominante de comercialização utilizada pelo produtor.

A racionalidade limitada pode ser resumida em termos da condição de absoluta impossibilidade de os agentes dominarem e conseguirem processar a totalidade das informações necessárias para a tomada de decisão
Os oportunismos podem manifestar-se a partir da revelação incompleta ou distorcida de uma informação, notadamente dos esforços premeditados para equivocar, ludibriar, distorcer, ocultar, ofuscar ou confundir. $\mathrm{Na}$ transação T2, observa-se que a circulação de informações de preços e mercado da batata reno é precária para o produtor.

A informação do preço pode ser cara e difícil de obter, especialmente nas condições de fluxos de informação reduzidos. A dificuldade de se obter a informação do preço pode ser medida pelos intervalos entre o tempo em que os preços do mercado se tornam conhecidos e o momento da venda. O conhecimento da informação do preço com antecedência reduz os custos da transação visto 
que o produtor pode selecionar o mercado e planejar a sua deslocação ou não ao mercado para a venda do produto. Conforme a pesquisa, $81,6 \%$ obtiveram informação sobre o preço da venda da batata dias antes da venda.

A informação incorreta de preço é igualmente um custo para o produtor e fonte de oportunismo. Se a informação do preço não está correta, os vendedores rurais podem equivocadamente selecionar um mercado ou uma transação e vender seu produto a preço mais baixo, perdendo desse modo um possível lucro. Para 46,9\% dos produtores, o preço real de venda foi mais baixo do que o preço conhecido, e para $53,1 \%$ foi o mesmo ou mais alto. Nesse caso, os custos da transação podem ser baixos, pois o produtor selecionou o mercado que melhor pagava. Dos produtores que conheciam o preço dias antes da venda, $27,9 \%$, venderam a sua produção ao preço baixo que era esperado. Isso supõe que eles obtiveram informações erradas sobre a oferta e os preços no mercado escolhido. Esses resultados mostram que conhecer o preço com antecedência não confere aos produtores a segurança de que a transação será acertada com o preço conhecido, e favorece o oportunismo. Porém, esse preço serve como base para se buscar o melhor preço durante a negociação. Oportunismos podem ocorrer quando o produtor não tem capacidade para negociar.

As vendas previamente concordadas ajudam os produtores a baixar os custos de busca de informação para uma transação. Quando as vendas são acordadas previamente, não há nenhuma necessidade de procurar um comprador para o produto e recolher a informação do preço e do mercado. A maioria dos produtores acertou o preço de venda no momento da venda, $98 \%$ e as negociações do preço levaram até 30 minutos. Alguns produtores informaram que, por vezes, os atacadistas dão um tempo para o produtor pensar no preço proposto, enquanto vai procurando outros locais para a compra do produto. Nos casos em que o atacadista dá um tempo para pensar, revela-se que o produtor tem competência e detém informações que lhe permitem reduzir o oportunismo dos atacadistas.

As especificidades dos ativos do comerciante atacadista para essa transação são de capital humano, ativo físico, temporal e locacional. Os resultados da pesquisa apontam que $75,7 \%$ ganharam experiência na gestão do negócio vendendo, $83 \%$ dos atacadistas entrevistados estão no negócio há mais de 5 anos, e 24,3\% tiveram capacitação básica sobre gestão de pequenos negócios. Esses dados querem dizer que os atacadistas ambulantes não podem ser substituídos por outros quaisquer, sem prejuízo na eficiência na transação. O segundo tipo referese ao investimento realizado para adquirir uma permissão a fim de utilizar a banca e o espaço no armazém, ou então adquirir um local próprio para a realização das transações, cujas implicações vão além do custo monetário, pois existe o fator influência (relações de proximidade, amizade, região comum e religião) e a penetração na comissão de venda de batata. Os relacionamentos predominantes são a amizade, com $87,5 \%$ dos atacadistas; com parceria, $8,4 \%$, e com parentes no negócio, $4,2 \%$, o que mostra quanto isso influencia no ativo físico, tendo em vista que comercializar e armazenar o produto no pátio do mercado reduz a qualidade do produto e aumenta os riscos de falha na transação.

Os comerciantes atacadistas ambulantes defrontamse com a especificidade temporal. A batata reno é uma cultura altamente perecível e perde sua qualidade rapidamente. A falta de armazenagem refrigerada e a dependência de varejistas nos mercados, feiras e restaurantes, que compram em pequenas quantidades, fazem com que haja perdas significativas do produto. $A$ especificidade temporal, nesse caso, é mediana, pois o atacadista apenas compra a batata se houver a perspectiva de revendê-la rapidamente, como ficou constatado na pesquisa de campo.

As especificidadeslocacionais envolvemanecessidade de proximidade de algum recurso natural, energético, de insumos, em relação a aspectos estratégicos vinculados a estoques, centros de distribuição e especificidades ligadas a pontos comerciais. Quanto ao local da venda, ela baixa, pois $95,8 \%$ dos comerciantes atacadistas ambulantes inquiridos afirmaram que o local em que vendem a batata é adequado, portanto representa o mercado distribuidor, o qual varejistas e consumidores finais frequentam diariamente. Ao longo do Vale do Zambeze, existem dois locais em que os atacadistas podem adquirir a batata: nos distritos de Angónia e Tsangano, no planalto de Angónia, e no distrito de Gorongasa. Este último oferece pequenas quantidades de batata da variedade BP1 ou Mondial, já que ela produz somente na safra seca (de março a agosto). A fraca oferta faz com que a Região de Angónia seja a 
principal fornecedora de batata para o centro e o norte de Moçambique.

O Planalto de Angónia fica entre 250 e $850 \mathrm{~km}$ dos maiores centros de consumo. O meio de transporte mais usado é o caminhão, sem condições de refrigeração. Os produtores sem meios próprios, ficam entre 2 e 5 dias à espera do transporte. O atacadista, que fica até dois dias, representa $74 \%$ dos inquiridos, e os ficam mais de dois dias representam $26 \%$. Esse resultado agrava-se porque $45 \%$ dos atacadistas levam 2 dias até chegar ao mercado e os outros 55\% um dia até ao mercado distribuidor. Assim, a especificidade locacional é alta, em termos de aquisição da batata, considerando que a compra é feita em regiões distantes dos centros de consumo.

O produtor, por sua vez, apresenta especificidades de capital humano e de ativo físico medianas, mas alta especificidade temporal. A primeira especificidade refere-se à experiência de cultivo da batata, que exige o conhecimento de práticas e conhecimentos técnicos específicos de produção. A especificidade do ativo físico é mediana, porque o ciclo do produto não é elevado ( 90 a 120 dias) e o solo pode ser empregado para outras culturas, como foi observado no zoneamento agroecológico. $\mathrm{O}$ produtor utiliza normas técnicas largamente difundidas e que não exigem, necessariamente, conhecimentos fisticados, somente muita prática. Qualquer produtor que estiver interessado em produzir batata pode seguir facilmente a técnica de produção. A possibilidade de cultivo por parte do interessado é confirmada pelo número de produtores que aprenderam a produzir sem curso específico, os quais representam $88,0 \%$ dos produtores pesquisados. A especificidade temporal, por sua vez, é alta. A comercialização do produto precisa ser rápida devido ao rápido processo de deterioração. A sua armazenagem é problemática em razão do seu grande volume e a falta de condições de refrigeração no campo. De modo geral, os agricultores fazem a colheita somente quando são contatados pelos atacadistas ambulantes e, em casos extremos, transportam-na para o mercado ou a feira mais próxima da aldeia. As transações realizam-se diariamente entre o atacadista e os diferentes produtores, estando o primeiro sujeito à incerteza quanto à qualidade do produto e o segundo quanto ao preço, àquantidade e à variedade do produto.

A transação é altamente frequente para o atacadista, vez que ocorre diariamente, mas está sujeita a diferentes incertezas por parte dos agentes. Ela exige um contrato relacional, devendo existir cooperação, troca de informações, por causa da especificidade da batata e dos ativos envolvidos na sua produção, e pela presença de fortes barreiras à entrada de novos entrantes no mercado distribuidor. Os atacadistas que já fazem o negócio têm a seu favor a grande disponibilidade de informações sobre os preços (para o produtor, no atacado e no varejo), volume de oferta e qualidade. Eles conhecem as regiões produtoras, quando as safras começam, e a qualidade do produto que vão oferecer. Em relação aos produtores, também há barreiras de entrada no mercado. Em cada mercado, existem atravessadores que criam barreiras para os produtores que queiram vender sua produção no mercado. Por exemplo, no principal mercado distribuidor (Biri-wiri), os produtores são obrigados a entregar a batata aos atravessadores para comercializarem. Em caso de recusa, os atravessadores não o deixam vender, chegando o produtor a ficar ali uma semana para vender uma tonelada de batata, o que implica maiores custos na transação por causa da perda de qualidade do produto.

Para o produtor, a frequência da transação é mediana, uma vez que se realiza duas a três vezes durante o ano, embora com variações sazonais. As melhores transações e de maior valor monetário concentram-se de novembro a janeiro.

No que diz respeito às incertezas para o atacadista ambulante, elas relacionam-se com a qualidade do produto comprado, uma vez que uma parte dos comerciantes atacadistas compram a batata reno já ensacada em embalagens opacas, com a possibilidade de a batata comprada não corresponder à pretendida. Mais de setenta e cinco por cento dos atacadistas reconheceram a qualidade da batata fornecida pelos produtores.

Para o produtor, as incertezas referem-se à demanda por parte dos varejistas, com relação a preços, quantidade e variedades. Essa situação deve-se ao seu limitado acesso a essas informações, que estão com os ambulantes que as manipulam em proveito próprio. Os atacadistas ambulantes buscam informações sobre a produção por meio de "olheiros", geralmente recrutados entre os pequenos produtores. De acordo com a pesquisa, 22\% dos atacadistas entrevistados usam os seus trabalhadores para essa pesquisa, e 78\% contam com informações de 
produtores amigos e de outros intermediários da mesma zona de origem.

\subsection{Transação entre produtor e varejista $-T_{3}$}

A transação T3 envolve produtores, varejistas e empresa de refeições coletivas (restaurantes, bancas de fast food, centro sociais da empresas, entre outras.) do Vale do Zambeze.

Nas transações, os atributos frequência e especificidade de ativos do produtor não sofrem alterações. Porém, a intensidade do atributo incerteza se reduz, uma vez que o varejista especifica antecipadamente a quantidade e a variedade da batata. Do ponto de vista do varejista, verifica-se a existência de especificidade de capital humano (conhecimento da atividade), temporal, locacional e marca. A perecebilidade vale o mesmo que para o atacadista ambulante. . Apesar de a batata perder sua qualidade rapidamente, pelo giro diário, nem sempre ela enfrenta problemas dessa natureza.

As outras duas especificidades são muito importantes, porém não estão associadas diretamente à batata. Ambas dizem respeito ao conjunto de produtos comercializados pelos varejistas no mercado ou na feira. As altas especificidades locacional e relacionada à marca estão diluídas pelo número de produtos comercializados. A especificidade locacional refere-se à localização adequada da firma, que é um dos determinantes dos resultados das vendas dos produtos. Esse não é problema para a maioria dos varejistas da batata reno, que vendem seus produtos em mercados municipais ou mercearias, conhecidos pelos consumidores como locais de referência para a obtenção de frutos e hortaliças. Conforme a pesquisa, todos os varejistas afirmaram que a localização é ideal. A especificidade de marca é a imagem que os varejistas desfrutam junto aos seus clientes ou, mais precisamente, a perda da reputação, caso os consumidores não encontrem todos os produtos que desejam. Apesar de ser mais importante que a primeira, a especificidade de marca se dilui diante da variedade de itens disponíveis na loja, perdendo sua relevância. Os varejistas entrevistados comercializam tomate, cebola, legumes e por vezes feijões, além da batata. Nesse caso, está-se tratando do pequeno e médio varejo. No caso do grande varejo, tal especificidade é ainda menos importante por causa do número elevado de itens comercializados.

A especificidade de marca também está ligada à construção de um nome, de uma marca, de uma reputação em um determinado mercado, posicionamento de um determinado produto, marketing, promoção de vendas, entre outros fatores. Nas cidades de Chimoio, Nampula e Tete, os consumidores têm preferência pela batata da região do planalto de Angónia, a variedade Rosita, por ela possuir maior quantidade de matéria seca, o que reduz a quantidade de óleo usado durante a fritura, pelas possibilidades de produzir chips e pela resistência à perecibilidade. Em média dura 1 mês, se armazenada nas condições normais de temperatura e pressão. No campo, verificou-se que essa variedade é cultivada há 21 anos e os pequenos produtores resistem a substituir a semente por novas variedades mais produtivas. Ela adquiriu uma espécie de "marca" nesses mercados e nos países vizinhos (Malawi e Zâmbia). Segundo os atacadistas nas transações realizadas, $63 \%$ correspondem à variedade local e $37 \%$ às variedades brancas (BP1, B3), o que mostra o caráter de marca conquistado pela variedade local. Nos mercados de Beira e Quelimane, há preferência pelas variedades de polpa branca importadas. Contudo, tem havido um aumento gradual no consumo da batata nacional.

As transações que ocorrem diariamente para o varejista dos mercados e das feiras estão sujeitas a risco e incerteza quanto à qualidade e à quantidade. O produtor vende a batata embalada em sacos opacos e não admite que os compradores abram o saco para selecionar a batata. Ao comprar batata nessas condições, há riscos de a qualidade ser baixa. Os varejistas não podem ficar sem batata para oferecer ao consumidor e, além disso, esse produto dever ser da qualidade melhor possível. Esses riscos são baixos, pois os varejistas entrevistados compram os produtos com produtores de confiança, respeitados por fornecerem batata de boa qualidade.

\subsection{Formas de governança e arranjos contratuais - T2 e T3}

Os arranjos organizacionais de mercado e híbridas são as principais estruturas de governança entre os agentes da cadeia produtiva na comercialização da batata reno. O arranjo híbrido da coordenação representa $24 \%$ e de 
mercado representa $76 \%$ das transações, respectivamente, isto é, $24 \%$ dos produtores fazem suas vendas diretamente no mercado, enquanto $76 \%$ vendem por intermediários assim distribuídos: $74 \%$ são atacadistas ambulantes e 2 varejistas. Quanto à semente, entretanto, além da governança de mercado, também se verifica a governança híbrida com o governo e a integração vertical.

A governança de mercado caracteriza-se pela ausência de compromisso de longo prazo, pela presença de contratos completa e por mecanismo de preços. A capacidade de fornecer um local específico para as realizações anônimas entre compradores e vendedores constitui vantagem do mercado físico.

A forma de mercado (T3) favorece o produtor e intermediária informação a respeito do comportamento dos preços dos produtos comercializados, em razão da informação ser pública nessa situação. Tal fato reduz o risco de existência de elevado diferencial de preços entre os concorrentes. Por outro lado, a governança de mercado não assegura o nível de qualidade e o volume do produto, que depende da disponibilidade dos fornecedores no momento da aquisição. Assim, apesar de apresentar custos de transação mais elevados, a existência da governança de mercado ainda tem um papel informativo importante para as transações entre os agentes da cadeia de batata.

Dois arranjos híbridos têm surgido para governar as transações entre produtor e atacadista (T2) e produtor e varejista (T3) na cadeia produtiva de batata. As duas primeiras formas referem-se à parceria na produção. $\mathrm{Na}$ parceria, o atacadista/varejista fornece ao produtor os insumos necessários à produção, interferindo diretamente no processo produtivo, objetivando obter maior garantia de disponibilidade de produto de alta qualidade e maior lucro. Tal forma de governança exige a adoção de algum tipo de controle da produção por parte do atacadista/ varejista, o que incorre em custos adicionais. $\mathrm{O}$ efeito reputação associado aos sistemas de informação fiel inibe o comportamento oportunista de ambas as partes.

A terceira forma refere-se a contratos informais de fornecimento. Nesse tipo de arranjo, o compromisso entre os agentes baseia-se principalmente na confiança mútua, não existindo qualquer tipo de documento formal como garantia da transação. Normalmente, em tais contratos a determinação do preço ocorre após a entrega do produto, sendo baseada nas condições vigentes no momento da transação. Apresentam um mecanismo de adaptação cooperativo referente ao preço e surgem em relações de longo prazo recorrentes. Novamente, o efeito reputação nos sistemas de informação baseados em redes de comunicação desempenha o papel principal na salvaguarda de tais contratos.

A adoção de contratos de fornecimento ou alianças informais reduz os custos de organizar hierarquicamente as transações, sendo uma alternativa mais viável que a integração vertical. A combinação de aprendizado mútuo e coletivo e o efeito reputação, que derivam da repetição da transação dentro de uma relação de longo prazo, sustentam os compromissos informais oriundos da dependência bilateral. A ação conjunta fornece o suporte necessário para a efetividade dos mecanismos.

Uma forma de os produtores reduzirem os riscos da falta de semente é recorrer à integração vertical, o que elimina as incertezas entre as relações na cadeia produtiva, permanecendo apenas as incertezas com relação à demanda (mercado), embora essas sejam as principais. A importância da integração vertical na primeira etapa do processo produtivo está vinculada à garantia de fornecimento da semente a um preço de custo e não de mercado. A integração vertical na produção de semente é uma das estratégias de 39\% dos produtores entrevistados. Os principais produtores avançam na integração até chegarem à distribuição, mas poucos integram toda a cadeia (até o cliente final). A preocupação com a integração está mais relacionada com a detenção, o controle da atividade, o estabelecimento de parcerias e a construção de relacionamentos ao longo da cadeia produtiva.

\section{CONSIDERAÇÕES FINAIS}

A cadeia produtiva de batata reno é uma das menos desenvolvidas em Moçambique, pois apresenta ausência de padrões mínimos de referencia efetiva e assimetria excessiva no sistema de informações. A cadeia produtiva de batata reno do Vale do Zambeze vem sofrendo um rápido processo de transformação do padrão de competição centrada nas empresas individuais para a coordenação da cadeia produtiva. A busca de melhor desempenho ocorre por meio da comparação mais estreita entre agentes visando principalmente elevar a qualidade do produto comercializado. 
A falta de informações a respeito do mercado da batata reno é o principal problema enfrentado pelos agentes da cadeia produtiva. O sistema atual de comercialização baseada nos mercados físicos rurais e urbanos, não tem capacidade de transmitir eficientemente informações sobre preços, condições de mercado, consumo e qualidade. A pesquisa de campo verificou que existem clubes de batata e associações distritais em fase prematura, mas que estão apoiando os membros com informações sobre mercado e preços. Observa-se que o setor público não tem padrões e classificações para a cadeia produtiva, prejudicando o desenvolvimento do setor.

As infraestruturas de apoio são precárias, não contam com câmaras frias e apresentam todas as estruturas logísticas (estradas, armazéns, entre outras) malcuidadas e obsoletas. Consequentemente, a incerteza, tanto endógena quanto exógena, é elevada, e o mercado físico continua sendo necessário para coordenador o fluxo da produção e da comercialização.

Complementando o cenário da cadeia produtiva de batata reno do Vale do Zambeze, as estruturas logísticas e administrativas são obsoletas e ineficientes, não permitindo a concretização de ganhos de escala gerando altos custos logísticos que enfraquecem todos os elos da cadeia.

A análise das transações enfocadas neste trabalho sugere que os consumidores estão cada vez mais exigentes quanto à qualidade e à procedência dos produtos agrícolas. O mercado de batata, pouco a pouco, vai procurando diferenciar seu produto em resposta às necessidades e aos desejos dos consumidores, o que leva a uma crescente segmentação desse setor. Essa segmentação pode ser verificada pelo crescimento da participação no mercado de novas variedades de batata (BP1, Mondia e Liseta), assim como de uma ampla gama de novos produtos de batata processada importada da África do Sul. Desse modo, os atacadistas e os varejistas são forçados a aumentar o nível de exigência com os seus fornecedores de batata in natura. Há uma diferenciação e segmentação do consumo no mercado de batata reno em Moçambique e no Vale do Zambeze. As capitais provinciais do centro do país preferem batata de alta qualidade, diferentemente da zona norte e de algumas cidades do centro do país, que consomem batata de acordo com o preço.
Essa movimentação do consumidor final, portanto, cumpre um papel crucial no aumento da importância das significativas incertezas envolvidas na produção agrícola para a determinação de formas de governança. Os agentes da cadeia passam a caminhar em busca de arranjos contratuais que diminuam as dúvidas quanto à disponibilidade de produtos de alta qualidade que o consumidor está cada vez mais exigindo. Além disso, maiores exigências quanto ao produto e, portanto, na sua produção podem ser interpretadas como um aumento na especificidade de ativos específicos, o que também leva a formas de governança que forneçam a possibilidade de adaptação cooperativa e mais distantes da governança via mercado.

Da análise dos resultados, observa-se que as formas de governança verificadas entre as transações $\mathrm{T}_{2}, \mathrm{~T}_{3}$ e $\mathrm{T}_{4}$ apresentam três formas de governança distintas - uma de mercado e duas híbridas -, relacionadas com as peculiaridades das transações. As transações $\mathrm{T}_{1}$ apresentaram integração vertical na produção de sementes certificadas. As transações que envolvem a cultura caracterizam-se por apresentar uma elevada especificidade de ativos, principalmente para o produtor rural, alto grau de incerteza e alta frequência. À medida que a especificidade dos ativos se eleva, a tendência é que os contratos evoluam da governança tipo mercado para as formas híbridas.

\section{Os principais mecanismos de coordenação identificados foram:}

Sistemas de informações: medianas redes interpessoais de produtores e intermediários circulam as informações sobre mercados e preços. Os boletins semanais na internet, jornal impresso, programas da rádio usados pelo SIMA só atingem os atacadistas e os varejistas da cadeia dos centros urbanos. Os sistemas de informação implementados estão voltados basicamente para ampliar a "racionalidade buscada" e melhorar os processos decisórios em nível de cadeia.

Sistemas de incentivos: constituem preços diferenciados em virtude da qualidade da batata, empréstimos diretos e indiretos e projetos que buscam uma maior integração dos produtores no mercado por meio da capacitação sobre pesquisa de preços, seleção de intermediários e poupança e crédito. As instituições 
de microfinanças e FIL são os meios de crédito usados para incentivar a produção agrícola pela disponibilização de crédito para a produção e a comercialização. A modernização e a intensificação da produção de batata reno estão sendo implementadas no quadro da estratégia da revolução verde de 2007. As ações de coordenação em curso estão orientadas para o incremento dos níveis de produção, produtividade e renda dos produtores da cultura.

Sistemas de orientação $\boldsymbol{e}$ assistência: a extensão rural e a difusão tecnológica pelos serviços distritais de atividade econômica são fracas. As redes sociais rurais e os projetos em conjunto com os agentes do ambiente organizacional visam ao desenvolvimento de pesquisas aplicadas no setor de produção. A ADIPSA coordena a capacitação profissional das associações mediante aconstituição e legalização das associações; a capacitação em associativismo e liderança; a gestão administrativa e de pequenos negócios e o acesso serviços a financeiros.

Com ações de parceria e cooperação, procura coordenar todas as atividades, desde apoio em tecnologia, fornecimento de insumos, produção e comercialização da batata. Os produtores usam redes sociais de ajuda mútua para a assistência técnica à produção. Para a comercialização, os produtores, por meio das redes sociais coordenam o uso do mesmo transporte nas idas ao mercado como forma de reduzir os custos de transação. As parcerias entre produtores e atacadistas estão no financiamento à produção e ao escoamento da batata.

Sistema de controle: Existe uma fraca fiscalização da qualidade dos insumos (venda de produtos químicos não licenciados), na produção e nos mercados em geral por parte dos organismos públicos. Somente há um controle da qualidade da batata efetuado pelos atacadistas ao comprarem a batata nas explorações agrícolas. Portanto, o principal instrumento que rege as transações é a adesão às redes sociais, relações interpessoais e os contratos informais baseados no conhecimento mútuo das condições que regem negócios específicos.

\section{LIMITAÇÕES DO ESTUDO}

Do ponto de vista metodológico a principal limitação do estudo se relaciona com o próprio método utilizado na pesquisa. Os estudos de natureza qualitativos são limitados na extrapolação e generalização dos resultados para situações semelhantes. Entende-se por situações semelhantes o contexto institucional e de mercado que envolve a cadeia produtiva estudada e as características das inúmeras variedades da batata produzidas.

\section{REFERÊNCIAS}

ARBAGE, L. P. Custos de Transação e seu impacto na formação e gestão da cadeia de suprimento: Estudo de caso em estruturas de governança híbridas do sistema agroalimentar no Rio Grande do Sul. Tese Doutoramento, Programa de Pós-Graduação em Administração, PPGA/UFRGS, 267 p Porto Alegre, 2004.

DEMO, P; DOMIGUEZ, C. S.; WALKER, T. The potato sub-sector and strategies for sustainable seed production in Mozambique. Report of two-week potato sub-sector. March 2006.

FARINA, M.M.Q; AZEVEDO, P.F.; SAES, M.S.M. Competitividade: Mercado, Estado e Organizações. São Paulo: Editora Singular, 1997.

FARINA E.M.M.Q. ZYLBERSZTAJN, D. Competitividade e Organização das Cadeias Agroindustriais. Costa Rica: IICA Instituto Interamericano de Cooperação para a Agricultura, 63p 1994

FURLANETTO, E.L. Formação das Estruturas de Coordenação nas Cadeias de Suprimentos: Estudos de Caso em Cinco Empresas Gaúchas. Tese de Doutorado, Programa de PósGraduação em Administração, PPGA/UFRGS, 291 p., 2002. Disponível em: www.lume.ufrgs.br/handle/10183/2114. acesso em 8 de Outubro de 2009.

FAOTAT (2007) . www.fao.org/es/esa/ Acesso: Fev/2009.

GABRE-MADHIN, E. Z. Market Institutions, Transaction Costs, and Social Capital in the Ethiopian Grain Market. INTERNATIONAL FOOD POLICY RESEARCH INSTITUTE WASHINGTON, D.C. RESEARCH REPORT 124, 2001.

MACHADO, E. L. O papel da reputação na coordenação vertical da cadeia produtiva de frutas, legumes e verduras frescos. Tese de Doutorado. Faculdade de Economia, Administração e Contabilidade. FEA/USP, 182p, 2002.

MATTAR, Fauze Najib. Pesquisa de marketing: metodologia, planejamento, execução, análise. São Paulo: Atlas, 1994.

MINISTÉRIO DA AGRICULTURA. Direcção de Economia, Trabalho de Inquerito Agrícola (TIA) - Resultados preliminares do TIA ,2006, Maputo, Março 2007.

NORTH, D. Institutions, institutional change and economic performance. Cambridge: Cambridge University Press, 1990.

SILVA, C. L. Competitividade internacional da indústria de papel de imprimir e escrever brasileira sob a ótica da cadeia de valor. Tese de doutorado. Florianópolis 2002. Disponível em: http://teses.eps.ufsc.br/defesa/pdf/12220.pdf. Acesso: Mar/2009 
WILLIAMSON, O.E.The economic institutions of capitalism. New York: Free Press, 1985.

The Economic Institutions of Capitalism. New York: The Free Press, 1985. 450 p.

ZYLBERSTAJN, D. Estrutura de governança e coordenação do agribusiness: uma aplicação da nova economia das instituições. 1995. 238f. Tese (Livre Docência) - Faculdade de Economia, Administração e Contabilidade, Universidade de São Paulo, São Paulo, 1995.

ZYLBERSTAJN, D. e LAZZARINI, S.G. On the Continuity of contracts: A study of the Brazilian Seed Industry. 1997. 